\title{
Effects of family history and consanguinity in primary immunodeficiency diseases in children in Qatar
}

\author{
Mohammad Ehlayel ${ }^{1,2^{*}}$, Abdulbari Bener $^{3,4}$, Mohammad Abu Laban $^{5}$ \\ ${ }^{1}$ Weill Cornell Medical College, Doha, Qatar; ${ }^{\text {Corresponding Author: mehlayel@gmail.com }}$ \\ ${ }^{2}$ Section of Pediatric Allergy-Immunology, Department of Pediatrics, Hamad Medical Corporation, Doha, Qatar \\ ${ }^{3}$ Department of Medical Statistics and Epidemiology, Hamad Medical Corporation, Department of Public Health, Weill Cornell \\ Medical College, Doha, Qatar \\ ${ }^{4}$ Department of Evidence for Population Health Unit, School of Epidemiology and Health Sciences, University of Manchester, Man- \\ chester, UK \\ ${ }^{5}$ Section of Pediatrics Hematology-Oncology, Hamad Medical Corporation, Department of Pediatrics, Doha, Qatar
}

Received 31 March 2013; revised 30 April 2013; accepted 13 May 2013

Copyright (C) 2013 Mohammad Ehlayel et al. This is an open access article distributed under the Creative Commons Attribution License, which permits unrestricted use, distribution, and reproduction in any medium, provided the original work is properly cited.

\section{ABSTRACT}

Background: The high consanguinity in Middle East increases the risk of genetic diseases, including primary immunodeficiency diseases (PID). Objectives: This study was aimed at determining the rate of positive family history of PID, the overall rate and type of consanguinity, and their effects on delay age during diagnosis of PID. Materials and methods: A retrospective analysis was conducted on 131 children with PID (aged 0 - 14 years) managed at Hamad General Hospital during 1998-2012. Results: Data on 131 patients (75 males \& 56 females) of 82 families was analyzed. The most common phenotype of PID was predominantly antibody deficiency (23.7\%). The onset age was 24.01 months and delay age 18.7 months. Family history of PID was $66.4 \%(38.7 \%$ in predominantly antibody deficiency and $100 \%$ in diseases of immune dysregulation). Positive family history significantly $(p=0.004)$ reduced the delay age of PID diagnosis by $\mathbf{5 2 . 9 \%}$. The consanguinity rate was $61.1 \%(32.3 \%$ in the predominantly antibody ID to $96 \%$ in the phagocyte defects group), where paternal cousin ranked the highest type (57.5\%). Conclusions: This study indicates that family history is common in children with PID and helpful in reducing the delay age. Consanguinity among families of affected children is also high (higher than healthy population). Paternal parallel cousin marriages are the most common type of consanguinity. For a practicing physician, family history is a simple and useful tool when suspecting PID in children. Primary preven- tion of PID in Middle East communities should consider consanguinity reduction through public awareness and education and premarital counseling programs.

Keywords: Pediatric; Primary Immunodeficiency Diseases; Family History; Consanguinity

\section{INTRODUCTION}

Primary immunodeficiency diseases comprise a group of rare, heterogeneous, genetically diverse disorders that affect specific components of immune systems and eventually result in defective differentiation, function, or both of these components [1].

With the extensive molecular and genetic research trying to determine the underlying defects in the various types of PID, the diagnostic criteria and the classification systems have been undergoing regular revisions and updates to meet the increasing list of new diseases $[2,3]$. However, many types of PID still do not follow a single pattern of inheritance although they are obviously influenced by genetic factors [4].

In a particular community, consanguinity does not increase rate of autosomal recessive disorders only, but also multifactorial diseases [5]. Since many communities of Middle East region, including Qatar, share similar social, cultural, and religious ties that govern marriage habits, consanguinity is quite common in [5-8], and it has been shown that it increases the risk of genetic disorders [5].

During the last few years, reports from communities with high rates of consanguinity indicate high rate of PID in the following communities: Saudi Arabia [9], Egypt [10], Iran [11], Kuwait [12], Morocco [13], Oman [14], 
Tunisia [13], Turkey [15]. With the high consanguinity rate in the Qatari population, genetic disorders and congenital birth defects were found to be relatively high for the population size of the country [5].

\section{OBJECTIVES}

In this study our objectives were 1) to determine the overall rate and the most common type consanguinity among children diagnosed ( 0 - 14 years) with PID in Qatar, 2) to determine the rate of family history of PID among these children, 3) to explore the possible effect of consanguinity or family history on the delay age (time between the age of onset of symptoms and the age of diagnosis) of PID in these children.

\section{METHODS AND PATIENTS}

All children who were diagnosed (by M.E.) with PIDs at Section of Pediatric Allergy-Immunology at Hamad General Hospital between 1998 and 2012 are included in this retrospective study.

Each patient's record was reviewed and information was collected on a specially prepared standard data collection form, including information such demographic data (age, sex, nationality, etc.), PID diagnosis (clinical diagnosis, onset age and diagnosis age), clinical manifestations (clinical conditions, treatment, and outcome), and laboratory investigations (including blood counts, immunological, microbial workup, and radiological procedures and genetic tests, etc.). Advanced molecular testing for genetic mutations of PID were sent abroad since these tests are not routinely available in Qatar.

PID diagnosis and classification was made according to the clinical and laboratory criteria introduced by the European Society of Immunodeficiency (ESID) [2] and The International Union of Immunological Societies (IUIS) Primary Immunodeficiency Diseases Classification Committee [2,3]. The Research Ethics Committee at Hamad General Hospital of Hamad Medical Corporation approved this study.

\section{STATISTICAL ANALAYSIS}

Using the Statistical Packages for Social Sciences (SPSS, Window version No.19), data was coded and entered into and processed on an IBM-PC compatible computer. Frequency distributions, one and two-way tabulations were obtained. Student-t test was used to ascertain the significance of differences between mean values of two continuous variables and confirmed by non-parametric Mann-Whitney test. Chi-square analysis was performed to test for differences in proportions of categorical variables between two or more groups. Pearson's correlation test was used to calculate correlation coefficient. In $2 \times 2$ tables, the Fisher's exact test (two-tailed) replaced the Chi-square test if the assumptions underlying Chi-square violated namely in case of small sample size and where the expected frequency is less than 5 in any of the cells. The level $p<0.05$ was considered as the cut-off value for significance.

\section{RESULTS}

\subsection{Patients' Characteristics}

A total of 131 patients ( 0 - 14 years) with PID belonging to 82 families are presented in this study, Table 1. They are $75(57.3 \%)$ males and $56(42.7 \%)$ females with male-to-female ratio of 1.34:1. The overall mean age was $69.9 \pm 47.0$ months with no significant difference between mean age of males and that of females $(p=0.344)$. Predominantly antibody immunodeficiencies (ID) was the most common phenotype (23.7\%), followed by other well-defined ID syndromes $(22.9 \%$,), combined T and B cell ID (19.1\%), congenital defects of phagocyte number, function, or both (19.1\%), diseases of immune dysregulation $(12.2 \%)$, and defects of innate immunity $(3.1 \%)$. Complement deficiencies were not identified in our patients in spite of the routine testing for complement deficiencies in patients referred to our pediatric allergy immunology services.

The overall mean onset age was 24.01 months $(0-137$ months), the age of diagnosis was 42.2 months ( 0 - 138 months), and the delay age was 18.7 months (0 - 139 months). However, there was a marked variation in these ages between the categories of PID categories (Figure 1). The combined $\mathrm{T}$ and $\mathrm{B}$ cell ID phenotype presented with the earliest onset age and the least delay age, while other well-defined ID syndromes presented with the latest onset age and the largest delay age (Figure 1).

\subsection{Family History and PID}

Overall, a positive family history of PID was observed in 87 patients $(66.4 \%)$, with the highest frequency among diseases of immune dysregulation (16 patients, 100\%) and phagocyte defects (23 patients, 92\%), but lowest among the predominantly antibody ID (12 patients, $38.7 \%$ ) category, Table 1. In families with positive family history of PID, the number of affected childen (mean \pm SD) per family was $2.22 \pm 1.31$.

In our patients, family history of PID showed no significant association with male-to-female ratio $(p=0.897)$. When compared to negative family history of PID, the overall positive family history significantly $(\mathrm{p}=0.004)$ reduced the delay age of PID diagnosis by $52.9 \%$ (10.4 \pm 2.2 months vs. $22.1 \pm 3.7$ months), Table 2 . However, there was no significant difference between delay ages with positive family history compared with those with negative family history at the level of each PID category, Table 2. 
Table 1. Distribution of PID categories per families' characteristics.

\begin{tabular}{|c|c|c|c|}
\hline PID category & No. of Families N (\%) & Ratio of children per family & Family history of PID \\
\hline $\mathrm{T}$ and $\mathrm{B}$ cell combined ID & $17(20.7 \%)$ & $1.47: 1$ & $19(76 \%)$ \\
\hline Other well-defined syndromes with ID & $20(24.4 \%)$ & $.1 .5: 1$ & $17(54.84 \%)$ \\
\hline Predominantly antibody deficiency & $23(28.0 \%)$ & $1.35: 1$ & $12(38.7 \%)$ \\
\hline Diseases of immune dysregulation & $6(7.3 \%)$ & $2.67: 1$ & $16(100 \%)$ \\
\hline Phagocyte defects & $12(14.6 \%)$ & $2: 1$ & $23(92 \%)$ \\
\hline Defects of innate immunity & $4(4.9 \%)$ & $1: 1$ & 0 \\
\hline Total & $82(100 \%)$ & & $87(66.4 \%)$ \\
\hline
\end{tabular}

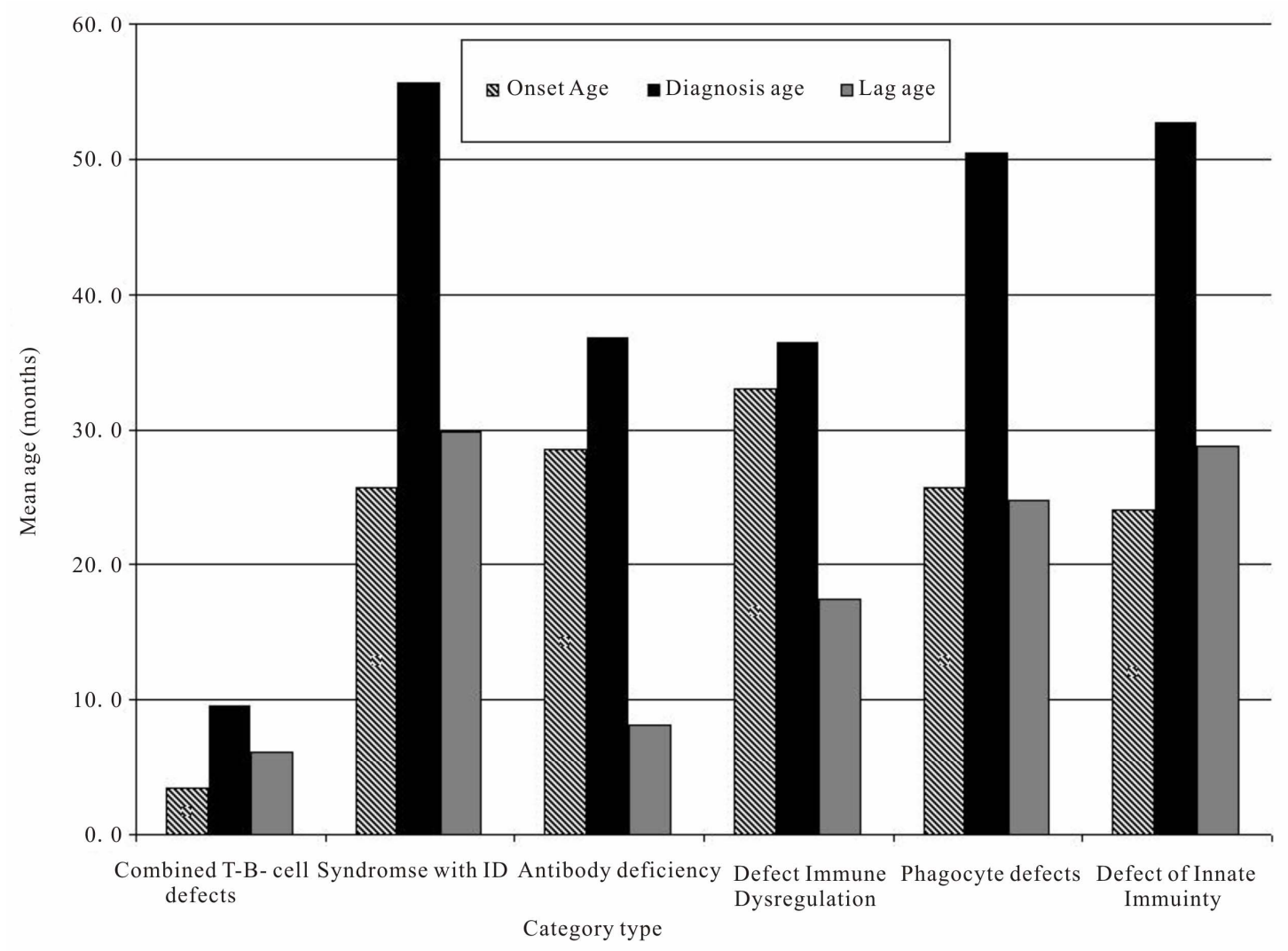

Figure 1. Onset age, diagnosis age and delay age for each categories of PID.

\subsection{Consanguinity and PID}

In this study, of the 82 families a total 127 patients (96.4\%) belonging to of 79 families $(96.3 \%)$ came from socially consanguinity-permissible culture, and 3 families $(3.7 \%)$ are consanguinity-impermissible. Since the latter number is quite small, the analysis of consanguinity was done on the 82 families.

The rate of consanguineous marriages was $61.1 \%$ with marked variation among the different ID categories, ranging from $32.3 \%$ in the predominantly antibody ID to $96 \%$ in the phagocyte defects group, Table 3 .

Generally, the rate of consanguinity among our patients was significantly higher than the non-consanguinity rate $(61.1 \%$ vs. $38.9 \%, p=0.0117)$. Compared to other types of consanguineous marriages, paternal parallel cousin types revealed the highest rate of $57.5 \%$, Table 2 . The consanguinity rate showed no significant association with male-to-female ratio among our PID patients $(\mathrm{p}=$ $0.258)$.

\section{DISCUSSION}

In this study, the predominantly antibody deficiency was the most common group of PID (23.7\%), followed by other well-defined ID syndromes $(22.9 \%)$. This trend was also reported in other studies from Kuwait [16], South Africa [17] and India [18]. In renowned PID regis- 
Table 2. Delay age and effect of family history of PID in 131 children in Qatar.

\begin{tabular}{|c|c|c|c|}
\hline \multirow{2}{*}{ PID category } & \multicolumn{3}{|c|}{ Delay age (months, mean \pm SD) } \\
\hline & Positive family history & Negative family history & p-value \\
\hline Combined ID $(n=25)$ & $2.6 \pm 0.9$ & $10.2 \pm 6.0$ & 0.228 \\
\hline Other well-defined syndromes $(\mathrm{n}=30)$ & $20.7 \pm 10.3$ & $31.6 \pm 5.8$ & 0.399 \\
\hline Predominantly antibody deficiencies $(n=31)$ & $6.8 \pm 3.4$ & $13.2 \pm 3.9$ & 0.415 \\
\hline Immune dysregulation $(\mathrm{n}=16)$ & $8.4 \pm 3.8$ & $29.4 \pm 18.1$ & 0.220 \\
\hline Phagocyte defects $(\mathrm{n}=25)$ & $11.2 \pm 5.1$ & $37.3 \pm 9.6$ & 0.029 \\
\hline Defects of innate immunity $(n=4)$ & none & $28.7 \pm 10.5$ & - \\
\hline All phenotypes $(\mathrm{n}=131)$ & $10.4 \pm 2.2$ & $22.1 \pm 3.7$ & 0.004 \\
\hline
\end{tabular}

Table 3. Type of parental consanguinity among children with PIDS.

\begin{tabular}{|c|c|c|c|c|c|c|c|}
\hline \multirow[b]{2}{*}{ PID category } & \multicolumn{4}{|c|}{$\begin{array}{l}\text { Type of Consanguinity } \\
\mathrm{N}(\%) \text { of category }\end{array}$} & \multirow{2}{*}{$\begin{array}{c}\text { Overall } \\
\text { consanguinity } \\
\text { N (\%category) }\end{array}$} & \multirow{2}{*}{$\begin{array}{l}\text { No consanguinity } \\
\mathrm{N} \text { (\%category) }\end{array}$} & \multirow{2}{*}{$\begin{array}{c}\text { Total } \\
\mathrm{N}\end{array}$} \\
\hline & $\begin{array}{l}\text { Double } \\
\text { cousins }\end{array}$ & $\begin{array}{l}\text { Maternal } \\
\text { cousins }\end{array}$ & $\begin{array}{l}\text { Paternal } \\
\text { cousins }\end{array}$ & $\begin{array}{c}\text { Distant } \\
\text { relatives }\end{array}$ & & & \\
\hline Combined ID & 6 & 1 & 12 & 2 & $21(84 \%)$ & $4(16 \%)$ & 25 \\
\hline Other well-defined syndromes & 2 & 6 & 6 & 0 & $14(46.7 \%)$ & $16(53.3 \%)$ & 30 \\
\hline Predominantly antibody deficiencies & 1 & 1 & 7 & 1 & $10(32.3 \%)$ & $21(67.7 \%)$ & 31 \\
\hline Immune dysregulation & 0 & 0 & 7 & 2 & $9(56.2 \%)$ & $7(43.8 \%)$ & 16 \\
\hline Phagocyte defects & 0 & 7 & 14 & 3 & $24(96 \%)$ & $1(4 \%)$ & 25 \\
\hline Defects of innate immunity & 0 & 0 & 0 & 2 & $2(50 \%)$ & $2(50 \%)$ & 4 \\
\hline All phenotypes & $9(11.2 \%)$ & $15(18.8 \%)$ & $46(57.5 \%)$ & $10(12.5 \%)$ & $80(61.1 \%)$ & $51(38.9 \%)$ & 131 \\
\hline
\end{tabular}

tries, predominantly antibody deficiency category was observed to be the most common PID diseases in the CEREDIH report (43\%) [19], ESID Registry data report $(55.49 \%)$ [20]. Since many diseases of the predmoniantly antibody deficencies and other well-defined ID syndromes are autosomal recesive and they constitues together almost half of our cohort, male-to-female ratio $(1.34: 1)$ is not high in in this study.

Compared to reports from other Middle East countries, the mean delay age in making diagnosis of PID in our group (18 months) was less than that reported from Egypt (29.9 months) [10] and Kuwait (27.3 months) [12], but longer than that from Oman (15.4 months) [14] and Turkey (8 months) [15].

Positive family history is considered one of the main warning signs of PID among children by JMF [21]. We observed positive family history in $66.4 \%$ of our patients. This rate is higher than that reported by Reda, et al. from Egypt (23.4\%) [10], Khalilzadeh, et al. from Iran (33.9\%) [22], Golan, et al. from Israel (36.4\%) [23], Al-Tamimi, et al. from Oman (42\%) [14], Azarsis from Turkey (43.5\%) [15] and Al-Herz et al. from Kuwait (44\%) [16].

Unlike previous a report [12], our study showed that positive family history of PID has a significant $(\mathrm{p}<$ 0.004 ) effect on reducing the delay age of diagnosis of PID among children. Data compiled from various reports from Middle East countries particularly Egypt [10], Kuwait [12], Oman [14] and Turkey [15] clearly revealed an inverse relationship (correlation coefficient -0.44 ) between rate of family history of PID and delay in making diagnosis of PID, Figure 2. This is important since early diagnosis and institution of appropriate management reduce mortality and morbidity of PID. Conversely, delayed diagnosis results in significant infections including sinusitis, pneumonia, and sepsis and a high risk of deaths $[24,25]$.

Consanguinity with its adverse genetic effects on diseases among populations of different Middle East countries (where consanguinity is quite common) have been the focus of many studies [5-8]. Since PID is a heterogeneous group of disorders [1], the relationship of consanguinity and PID has explored in different studies and reviews [10-15].

In our cohort, the overall consanguinity was high $(61.1 \%)$, similar to that reported from Egypt (62.5\%) [10], Iran (65.6\%) [11], Turkey (73.9\%) [15], Kuwait 


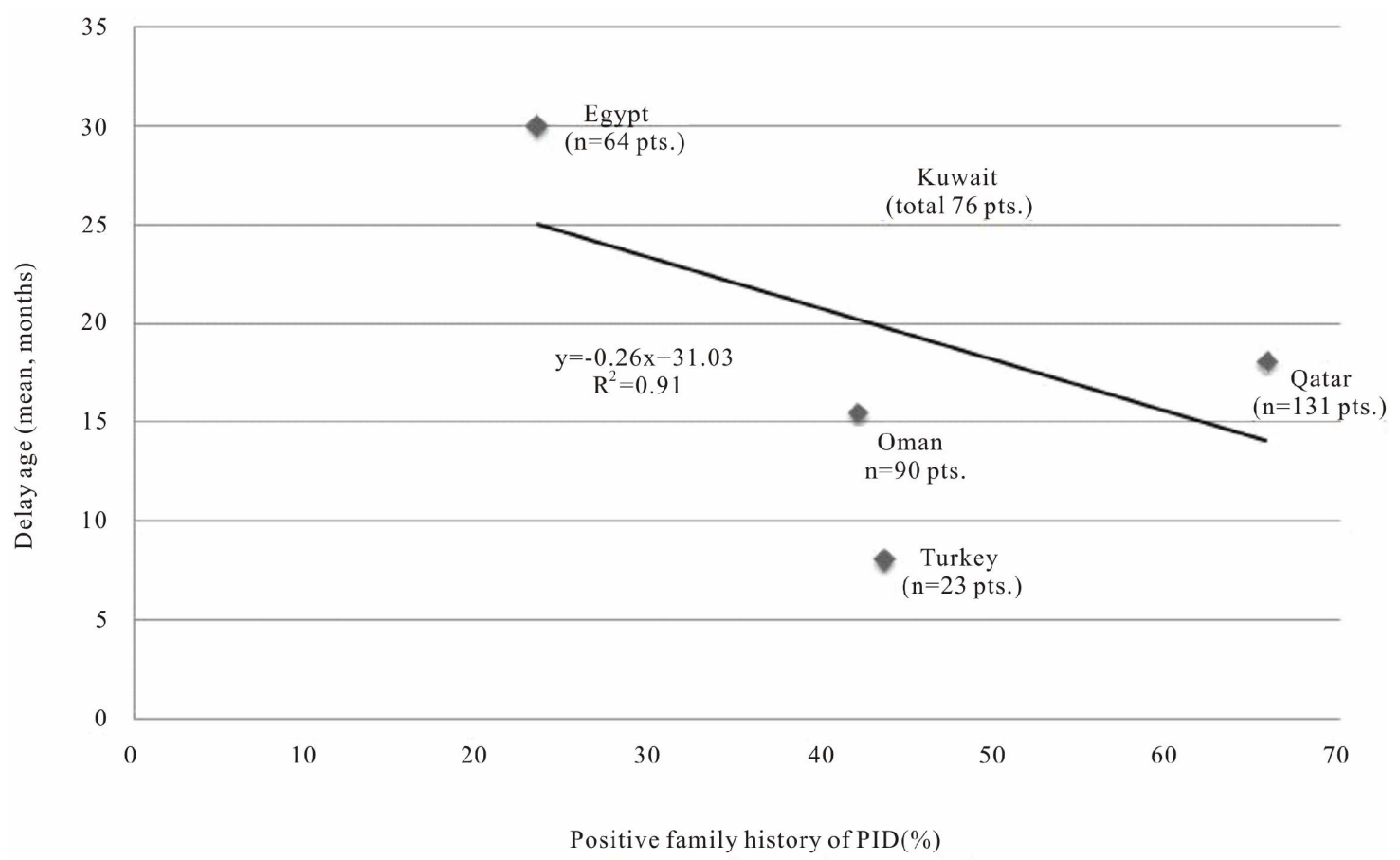

Figure 2. Relationship of positive family history on delay age of diagnosis of PID in 5 Middle East countries.

(75\%) [12] and Oman (81\%). [14]. It varied according to type of PID category: lowest (32.3\%) in predominantly antibody deficiency and highest $(96 \%)$ in phagocyte defects. The trend of high consanguinity rate in phagocyte defects was also noticed in reports from Iran $(75.5 \%)$ [11], Egypt (87.5\%) [10] and Kuwait (100\%) [12].

Various reports from Middle East countries, including Qatar, on consanguinity in PID indicate that the rate of consanguinity in cases of PID is $1.5-2$ folds higher than that among the healthy general population. In Qatar, we observed $61.1 \%$ compared to $51 \%$ in general population [26], $81 \%$ in Oman compared to $52 \%$ in general population [8], $75 \%$ in Kuwait compared to $42.1 \%$ in general population [27], $73.9 \%$ in Turkey compared to $22 \%$ in general population [28] and $65.5 \%$ in Iran compared to general population [11]. However, we could not observe any significant association between consanguinity and positive family history of PID or with delay age of diagnosis.

In our cohort, we found that first-degree cousins constituted $87.5 \%$ of the all consanguineous unions. This rate is higher than that from Iran, $(42.7 \%, \mathrm{n}=220$ of 515 patients) [11], Turkey (64.7\%) [15] or Kuwait (49.2\%) [12]. Among the various types of consanguineous unions, our study showed that paternal parallel first cousins ranked the highest $(57.5 \%)$, a result similar to that reported from Kuwait [12]. Unlike our results, Rezaei, et al. [11] reported that cross-cousins consanguineous unions were the commonest among first degree marriages (43.6\%, 96 of 220 cases). The possible explanation to this discrepancy is that in Arab countries, including Gulf states Qatar and Kuwait, the most common pattern of first cousin marriages is the paternal parallel cousins (in Qatar it constitutes $17.6 \%$ of all marriages [26]), a type of marriage that is not favored in Iran [11].

Limitations of this study are being a retrospective and from single center. Like many countries in the world that have no national PID registry or affiliation with international PID registries, data is generated in a way similar to this current study. However, this report being generated from Hamad General Hospital, the only tertiary care medical center in Qatar, where all PID patients managed at equal opportunity and receive medical care at no cost or very nominal charges to patients or families, gives a strength to this report due to standardization and consistency in management of these PID patients.

\section{CONCLUSIONS}

This present study indicates that family history is quite common in children with PID and helpful in reducing their delay age. Consanguinity among families of affected children is also high (higher than healthy general population). Paternal parallel cousins marriages are the commonest type of consanguinity.

For a practicing physician, family history is a simple and useful tool when suspecting PID in children. Primary prevention of PID in Middle East communities should consider reduction in consanguinity through public awareness and education and premarital counseling programs. 


\section{ACKNOWLEDGEMENTS}

The authors would like to thank Hamad Medical Corporation for their support and ethical approval (HMC Research Protocol No. 10078/10).

\section{REFERENCES}

[1] Rezaei, N., Bonilla, F.A., Sullivan, K.E., et al. (2008) An introduction to primary immunodeficiency diseases. In: Rezaei, N., Aghamohammadi, A. and Not-arangelo, L.D., Eds., Primary Immunodeficiency Diseases, Springer-Verlag, Berlin Heidelberg, 1-38.

[2] http://www.esid.org/clinical-diagnostic-criteria-for-pid-73 $\underline{-0}$

[3] Al-Herz, W., Bousfiha, A., Casanova, J.L., et al. (2011) Primary immunodeficiency diseases: An update on the classification from the international union of immunological societies expert committee for primary immunodeficiency. Frontiers in Immunology, 2, 54.

[4] Puck, J.M. and Nussbaum, R.L. (2007) Genetic principles and technologies in the study of Immune disorders. In: Ochs, H.D., Smith, C.I.E. and Puck, J.M., Eds., Primary Immunodeficiency Diseases: A Molecular and Genetic Approach, Oxford University Press, New York, 16-26.

[5] Bener, A. (2012) Consanguineous marriages and their effect on common diseases in the Qatari population. Genetic Disorders in the Arab World, Qatar 2012, 4, 30-39. http://www.cags.org.ae/publications.html

[6] Ben-Omran, T. and Abdul W.A. (2012) Genetic disorders in Arab populations: Qatar. Genetic Disorders in the Arab World, Qatar, 4, 60-65. http://www.cags.org.ae/publications.html

[7] Tadmouri, G.O., Nair, P., Tasneem, O., Mahmound, T.A.A., et al. (2009) Consanguinity and reproductive health among Arabs. Reprod Health, 6, 17. doi:10.1186/1742-4755-6-17

[8] Islam, M.M. (2012) The practice of consanguineous marriage in oman: Prevalence, trends and determinants. Journal of Biosocial Science, 44, 571-594. doi:10.1017/S0021932012000016

[9] Suliaman, F., Al-Ghonaium, A. and Harfi, H. (2006) High incidence of severe combined immune deficiency in the eastern province of Saudi Arabia. Pediatric Asthma, Allergy \& Immunology, 19, 14-18. doi:10.1089/pai.2006.19.14

[10] Reda, S.M., Afifi, H.M. and Amine, M.M. (2008) Primary imm unodeficiency diseases in Egyptian children: A single-center study. Journal of Clinical Immunology, 29, 343-351. doi:10.1007/s10875-008-9260-x

[11] Rezaei, N., Pourpak, Z., Aghamohammadi, A., et al. (2006) Consanguinity in primary immunodeficiency disorders, the report from Iranian primary immunodeficiency registry. American Journal of Reproductive Immunology, 56, 145-151. doi:10.1111/j.1600-0897.2006.00409.x

[12] Al-Herz, W., Naguib, K.K., Notarangelo, L.D. et al. (2011) Parental consanguinity and the risk of primary immunodeficiency disorders: Report from the Kuwait national primary immunodeficiency disorders registry. Interna- tinal Archieves of Allergy and Immunology, 154, 76-80. doi:10.1159/000319212

[13] Barbouche, M.R., Galal, N., Ben-Mustapha, I., et al. (2011) Primary immunodeficiencies in highly consanguineous North African populations. Annals of the New York Academy of Sciences, 1238, 42-52. doi:10.1111/j.1749-6632.2011.06260.x

[14] Al-Tamemi, S., Ibtisam, E. and Dennison, D. (2012) Primary immunodeficiency diseases in Oman: Five years' experience at Sultan Qaboos University Hospital. World Allergy Organiz Journal, 5, 52-56. doi:10.1097/WOX.0b013e318258830f

[15] Azarsiz, E., Gulez, N., Edeer Karaca, N., et al. (2011) Consanguinity rate and delay in diagnosis in Turkish patients with combined immunodeficiencies: A singlecenter study. Journal of Clinical Immunology, 31, 106111. doi:10.1007/s10875-010-9472-8

[16] Al-Herz, W. (2008) Primary immunodeficiency disorders in Kuwait: First report from Kuwait national primary immunodeficiency registry (2004-2006). Journal of Clinical Immunology, 28, 186-193. doi:10.1007/s10875-007-9144-5

[17] Naidoo, R., Ungerer, L., Cooper, M., et al. (2011) Primary immunodeficiencies: A 27-year review at a tertiary paediatric hospital in Cape Town, South Africa. Journal of Clinical Immunology, 31, 99-105. doi:10.1007/s10875-010-9465-7

[18] Verma, S., Sharma, P.K., Sivanandan, S., et al. (2008) Spectrum of primary immune deficiency at a tertiary care hospital. The Indian Journal of Pediatrics, 75, 143-148. doi:10.1007/s12098-008-0022-9

[19] CEREDIH: The French PID Study Group. (2010) The French national registry of primary immunodeficiency diseases. Clinical Immunology, 135, 264-272. doi:10.1016/j.clim.2010.02.021

[20] http://www.esid.org/esid registry.php

[21] Jeffrey Modell Foundation. (2009) 10 warning signs of primary immunodeficiency in children. www.info4pi.org/aboutPI/pdf/General10WarningSignsFI NAL.pdf

[22] Khalilzadeh, S., Boloorsaz, M.R., Baghaie, N., et al. (2011) Primary immunodeficiency in children: Report of seven years study. TANAFFOS: Journal of Respiratory Disease, Thoracic Surgery, Intensive Care and Tuberculosis, 10, $38-43$.

[23] Golan, H., Dalal, I., Garty, B.Z., et al. (2002) The incidence of primary immunodeficiency syndromes in Israel. The Israel Medical Association Journal, 11, 868-871.

[24] Joshi, A.Y., Iyer, V.V., Hagan, J.B., St. Sauver, J.L. and Boyce, T.G. (2009) Incidence and temporal trends of primary immunodeficiency: A population-based cohort study. Mayo Clinic Proceedings, 84, 16-22. doi:10.4065/84.1.16

[25] Al-Herz, W. and Moussa, M.A. (2012) Survival and predictors of death among primary immunodeficient patients: A registry-based study. Journal of Clinical Immunology, 32, 467-473.

[26] Bener, A., Hussain, R. and Teebi, A.S. (2007) Consanguineous marriages and their effects on common adult 
diseases: Studies from an endogamous population. Medical Principles and Practice Journal, 16, 262-267.

[27] Koc I. (2008) Prevalence and sociodemographic correlates of consanguineous marriages in Turkey. Journal of
Biosocial Science, 40, 137-148.

[28] Radovanovic, Z., Shah, N. and Behbehani, J. (1999) Prevalence and social correlates of consanguinity in Kuwait. Annals of Saudi Medicine, 19, 206-210. 